\title{
Entrevista com os familiares: um instrumento fundamental no planejamento da revelação diagnóstica do HIV/Aids para crianças e adolescentes
}

\author{
Interviews with family members: a fundamental tool \\ for planning the disclosure of a diagnosis of HIV/aids \\ for children and adolescents
}

\author{
Eliana Galano ${ }^{1}$ \\ Mario Alfredo De Marco ${ }^{2}$ \\ Regina Célia de Menezes Succi ${ }^{3}$ \\ Mariliza H. da Silva ${ }^{1}$ \\ Daisy Maria Machado ${ }^{3}$
}

${ }^{1}$ Centro de Referência e Treinamento das DST/Aids, Secretaria de Estado da Saúde de São Paulo. Rua Santa Cruz 81, Vila Mariana. 04121-000 São Paulo SP. elianagalano@gmail.com ${ }^{2}$ Departamento de Psiquiatria, Escola Paulista de Medicina, Universidade Federal de São Paulo.

${ }^{3}$ Disciplina de Infectologia Pediátrica, Escola Paulista de Medicina, Universidade Federal de São Paulo.

\begin{abstract}
The scope of this study was to present the participation of caregivers in creating strategies for disclosure of their condition to HIV-positive children, as well as discussing the interventions that might contribute to overcoming the difficulties that commonly prevent family members from accepting this process. The participants included 23 caregivers of 18 patients referred for diagnosis disclosure, monitored at two pediatric AIDS units in the municipality of São Paulo, Brazil. This is a qualitative study and data were collected through semi-structured interviews. The results showed that legitimating reasons why caregivers are reluctant to disclose the diagnosis to the children, as well as their motivations, are interventions that contribute to reduce resistance, facilitating the acceptance of disclosure. The collaboration of caregivers has provided valuable insights for conducting the work, and has enabled the establishment of a receptive and supportive relationship minimizing inhibitions that could be harmful to the continuity of the process.
\end{abstract}

Key words Acquired Immunodeficiency Syndrome, HIV, Child, Adolescent, Caregivers, Disclosure

Resumo O estudo teve como objetivo apresentar a participação dos cuidadores na construção de estratégias para a comunicação do HIV às crianças soropositivas, assim como, discutir as intervenções que contribuiriam para a superação das dificuldades que comumente impedem os familiares a aceitarem esse processo. Participaram 23 cuidadores de 18 pacientes com indicação para revelação diagnóstica, acompanhados em dois serviços de Aids pediátrica no município de São Paulo, Brasil. Trata-se de pesquisa qualitativa e os dados foram coletados através de entrevistas semidirigidas. Os resultados demonstraram que legitimar os motivos pelos quais os cuidadores relutam em divulgar o diagnóstico às suas crianças, assim como suas motivações, são intervenções que contribuem para diluir resistências, facilitando a aceitação da revelação. A colaboração dos responsáveis forneceu subsídios valiosos para o direcionamento do processo de revelação diagnóstica, além de ter possibilitado o estabelecimento de um vinculo receptivo e favorável, capaz de minimizar inibições que poderiam ser prejudiciais à continuidade do processo.

Palavras-chave Síndrome de Imunodeficiência Adquirida, HIV, Criança, Adolescente, Cuidadores, Revelação 


\section{Introdução}

Respeitar os direitos humanos das crianças e dos adolescentes que vivem com o HIV/aids tem sido preocupação constante dos profissionais e pesquisadores dedicados aos cuidados desses pacientes e à luta contra a epidemia. Dentre tantas inquietações, os desafios relacionados à revelação diagnóstica, são temas recorrentes e controversos, especialmente por tratar-se de uma enfermidade associada à morte, preconceito e discriminação. Apesar das recomendações sobre a importância de comunicar à criança sua condição sorológica ${ }^{1,2}$ os adultos tendem a adiar o confronto com a verdade e silenciam em sua presença por suporem protegê-las da amargura de saberem-se portadoras de uma enfermidade grave e incurável ${ }^{3,4}$.

Os profissionais também experimentam dificuldades no processo, pois compartilhar informações sobre a doença e o tratamento com essas crianças e jovens representa uma tarefa que envolve complexos fatores, dentre eles, a resistência das famílias que desejam manter o segredo em torno da infecção. Os resultados de estudos sobre a revelação diagnóstica enfatizam seus riscos e benefícios, sendo escassas as publicações que descrevem o desenvolvimento e a avaliação de estratégias utilizadas para facilitar a divulgação ${ }^{3}$.

Recomendações sobre como anunciar o diagnóstico às crianças e adolescentes soropositivos foram preconizadas no manual elaborado pelos membros do instituto de saúde de Nova York, um grupo que integra médicos e profissionais de diversas áreas ${ }^{1}$. No Brasil, um estudo qualitativo com cuidadores e adolescentes soropositivos realizado em São Paulo identificou que as ações adotadas pelos serviços para a condução do processo de revelação diagnóstica são muito diversificadas: algumas propostas são sistematizadas, pautadas em rotinas previamente estabelecidas, enquanto em outras os acontecimentos relacionados à abordagem do tema vão sendo resolvidos segundo necessidades individuais ${ }^{5}$.

A partir dessas constatações, definiu-se como objetivo central deste estudo apresentar a participação dos cuidadores na construção de estratégias para a comunicação do HIV às crianças soropositivas, assim como, discutir as intervenções que contribuem para a superação dos empecilhos que dificultam a aceitação desse processo pelos familiares. Por outro lado, a descrição deste modelo de trabalho poderá auxiliar os profissionais no desenvolvimento de políticas para que a prática da revelação diagnóstica possa ser realizada de forma mais efetiva e integrada no contexto do cuidado dessas crianças e adolescentes que vivem com o HIV/aids.

\section{Metodologia}

Esta pesquisa é parte de um projeto desenvolvido para estudar o Processo de Revelação Diagnóstica, compreendendo o período de abril de 2005 a setembro de 2006, com crianças e adolescentes desconhecedores de sua condição sorológica, acompanhadas em dois centros de referência em Aids pediátrica, no município de São Paulo, Brasil. Como parte deste projeto, de natureza qualitativa, 20 menores foram submetidos a uma Avaliação Psicológica (psicodiagnóstico) e depois encaminhados, se indicado, para a revelação diagnóstica.

Para alcançar os objetivos propostos, os cuidadores de pacientes com indicação para o processo da revelação diagnóstica foram encaminhados para entrevistas com questões abertas e perguntas específicas sobre os fatores que facilitam e dificultam a divulgação da doença às crianças, bem como os sentimentos, angústias, medos, crenças, entre outras preocupações relacionadas ao HIV/aids ${ }^{6,7}$. Além desses dados, investigaram-se os recursos emocionais dos responsáveis para o enfrentamento da enfermidade e possíveis sugestões para a realização do processo. A intervenção foi realizada em um ou mais atendimentos, dependendo da necessidade de cada caso, com duração aproximada de 1 hora e 30 minutos para cada encontro.

O material obtido do decorrer das entrevistas foi organizado em temas de forma a sintetizar os conteúdos considerados relevantes para a compreensão da construção do trabalho. $\mathrm{Na}$ primeira etapa, o texto foi decodificado por unidade de informação, seguido da criação de categorias através da compilação das unidades semelhantes. Este processo foi efetuado, comparando-se constantemente entre as unidades, estas com as categorias e as categorias entre $\mathrm{si}^{6}$. Além disso, a escolha de fragmentos de casos clínicos, combinados aos relatos de alguns responsáveis exemplificou a interpretação dada aos fenômenos e situações que foram observadas. A colaboração da equipe de investigação foi assegurada a fim de manter o rigor do processo de análise. Cada investigador fez individualmente o trabalho de síntese, codificação e categorização a partir da transcrição das falas para, na sequência, compartilhar e identificar a concordância e coerência na análise resultados com os demais pesquisadores ${ }^{8}$. 
O estudo foi aprovado pelos Comitês de Ética em Pesquisa das duas instituições participantes. As questões que se referem à pesquisa com a inclusão de seres humanos estiveram devidamente contempladas e respeitadas no Termo de Consentimento Livre e Esclarecido, tendo sido redigido segundo as diretrizes e orientações da Resolução no 196/96, do Conselho Nacional de Saúde ${ }^{9}$, bem como da Resolução nº 016/2000 do Conselho Federal de Psicologia ${ }^{10}$.

\section{Resultados}

Na fase de Avaliação Psicológica foram incluídas 20 crianças, sendo que uma não conclui o psicodiagnóstico e uma não teve indicação para o processo da revelação diagnóstica. As 18 crianças incluídas tinham idades variando de 79 a 137 meses, 10 eram do sexo masculino e todas adquiriram o HIV por transmissão vertical. (Quadro 1)

Foram entrevistados 23 responsáveis com idades entre 28 a 65 anos: 12 mães, 03 casais parentais, 04 avós maternas e 01 avó paterna.

\section{As intervenções realizadas junto aos cuidadores}

\section{A aproximação do momento da revelação como gerador de angústias: diluindo resistências}

A intensificação de temores e angústias nos familiares diante do momento para conversar sobre a doença com os pacientes exigiu compreensão cuidadosa, pois caso contrário impossibilitaria abordagens futuras que seriam cruciais e favoráveis para o processo. Atenção especial foi dada à identificação das principais barreiras e aspectos negativos envolvidos na comunicação do HIV à criança e ao adolescente, de forma a ampliar o conhecimento das representações da enfermidade para esses cuidadores. Da mesma forma, refletir amplamente sobre os benefícios e as motivações na comunicação da doença serviu como suporte para consolidar a disposição dos cuidadores de submeterem os pacientes à revelação diagnóstica da infecção pelo HIV/aids.

\section{Preocupações com a revelação}

Os resultados obtidos através da análise das entrevistas demonstraram que os responsáveis sentiam-se relutantes para a revelação diagnóstica por temerem que o conhecimento sobre a enfermidade pudesse causar na criança sentimentos de revolta e reações inesperadas, como por exemplo, atitudes de rebeldia e culpabilização dos pais pela doença.

Antes eu queria muito, agora que tá chegando eu tenho medo... de que ele fique revoltado e com raiva de mim. mãe de RSR

Eu tenho pavor das reações dele, de que ele fique revoltado. avó de RCC

Eu tenho muito medo que ela fique agressiva e revoltada com a gente. mãe de PPBA

Eu tenho medo que ele me culpe, fique revoltado, que leia alguma coisa ou que ouça alguém falar que é mil vezes melhor ter câncer do que Aids. mãe de MRS

O impacto negativo no estado de saúde físico e mental dos filhos e a opção pelo sigilo da doença com o intuito de protegê-los do estigma do diagnóstico, especialmente, entre aqueles que não guardam segredos, também foram aspectos que estiveram presentes na narrativa dos cuidadores.

Eu tenho medo dela cair doente e entrar em depressão. avó de MEOS

Ela não guarda segredo, sai do médico e fica falando para as outras crianças. Ela conta das consultas para todo mundo e se ela falar que tem Aids as pessoas vão se afastar dela, a gente sabe que é assim! mãe de AAS

Meu medo é que ela conte na escola e seja desprezada, que daí as pessoas tenham preconceito. mãe de SBM

Outras justificativas dadas pelos pais para a manutenção do segredo incluíram a imaturidade para o enfrentamento das situações adversas que envolvem a enfermidade e a não aceitação da doença resultando em desejo de transmitir o vírus para outras pessoas com a chegada da vida sexual.

Eu me preocupo com o que se passa nos pensamentos dele, que ele não consiga entender que o pai abandonou a gente por causa da doença. mãe de VCSD

Eu fico preocupada dele não aceitar bem a doença e que daí ele pode transmitir o vírus para outras pessoas... mãe de WGB

\section{Motivações para a revelação}

Os fatores que nortearam a disposição dos pais para a comunicação do HIV aos filhos abrangeram a curiosidade do paciente manifesta através de perguntas insistentes, sua capacidade de guardar segredo e a própria percepção dos pais sobre os direitos da criança em saber sobre a verdade de sua história.

Acho que agora é a hora certa porque ele tá muito, muito curioso e intrigado. mãe de SSX

Já está na hora, porque cada dia ele está mais curioso, fica me cobrando, a gente não vai poder 
Quadro 1. Características dos sujeitos da pesquisa

\begin{tabular}{|c|c|c|c|c|c|}
\hline Cuidador participante & Idade & Iniciais & Idade & Sexo & Sorologia dos pais \\
\hline Mãe & $28 \mathrm{a}$ & SBM & $6 a 7 m$ & $\mathrm{~F}$ & Mãe HIV+ / Pai falecido \\
\hline Mãe & $42 \mathrm{a}$ & GSP & $6 a 7 m$ & M & Mãe HIV+ / Pai (não tem contato) \\
\hline Mãe & $38 \mathrm{a}$ & LATR & $6 a 8 m$ & M & Mãe HIV+ / Pai falecido \\
\hline Mãe & $45 a$ & SSX & $7 \mathrm{a} 4 \mathrm{~m}$ & M & Mãe HIV+ / Pai falecido \\
\hline Mãe & $43 a$ & $\mathrm{RR}$ & $7 \mathrm{a} 4 \mathrm{~m}$ & $\mathrm{~F}$ & Pais HIV+ \\
\hline \multirow[t]{2}{*}{ Mãe e Pai } & $43 a$ & \multirow[t]{2}{*}{ VDMS } & \multirow[t]{2}{*}{$7 \mathrm{a} 5 \mathrm{~m}$} & \multirow[t]{2}{*}{$\mathrm{F}$} & \multirow[t]{2}{*}{ Mãe HIV+ / Pai HIV- } \\
\hline & $47 \mathrm{a}$ & & & & \\
\hline Mãe & $37 \mathrm{a}$ & DAC & $8 \mathrm{a} 10 \mathrm{~m}$ & $\mathrm{~F}$ & Pais HIV+ \\
\hline \multirow[t]{2}{*}{ Mãe e Pai } & $35 a$ & \multirow[t]{2}{*}{ LSS } & \multirow[t]{2}{*}{$9 \mathrm{a} 3 \mathrm{~m}$} & \multirow[t]{2}{*}{ M } & \multirow[t]{2}{*}{ Mãe HIV+ / Pai HIV- } \\
\hline & $40 \mathrm{a}$ & & & & \\
\hline Mãe & $43 a$ & MRS & $9 a 3 m$ & M & Pais HIV+ \\
\hline Avó materna & $61 \mathrm{a}$ & RCC & $9 \mathrm{a} 4 \mathrm{~m}$ & M & Pais HIV+ \\
\hline Mãe & $40 \mathrm{a}$ & GHS & $9 \mathrm{a} 4 \mathrm{~m}$ & M & Mãe HIV+ / Pai falecido \\
\hline Mãe & $39 \mathrm{a}$ & PPBA & $9 \mathrm{a} 9 \mathrm{~m}$ & $\mathrm{~F}$ & Pais HIV+ \\
\hline \multirow[t]{2}{*}{ Mãe e avó materna } & $35 a$ & \multirow[t]{2}{*}{ VCD } & \multirow[t]{2}{*}{$9 \mathrm{a} 10 \mathrm{~m}$} & \multirow[t]{2}{*}{ M } & \multirow[t]{2}{*}{ Mãe HIV+ / Pai (não tem contato) } \\
\hline & $63 \mathrm{a}$ & & & & \\
\hline Mãe & 33 a & RSR & $10 \mathrm{a} 2 \mathrm{~m}$ & M & Mãe HIV+ / Pai (não tem contato) \\
\hline \multirow[t]{2}{*}{ Mãe e avó paterna } & $40 \mathrm{a}$ & \multirow[t]{2}{*}{ WGB } & \multirow[t]{2}{*}{$10 \mathrm{a} 3 \mathrm{~m}$} & \multirow[t]{2}{*}{ M } & \multirow[t]{2}{*}{ Mãe HIV+ / Pai HIV- } \\
\hline & $65 a$ & & & & \\
\hline Avó materna & $53 \mathrm{a}$ & MEOS & $10 \mathrm{a} 5 \mathrm{~m}$ & $\mathrm{~F}$ & Pais falecidos \\
\hline Avó materna & $59 a$ & MIM & $10 \mathrm{a} 6 \mathrm{~m}$ & $\mathrm{~F}$ & Pais falecidos \\
\hline \multirow[t]{2}{*}{ Mãe e Pai } & $45 \mathrm{a}$ & \multirow[t]{2}{*}{ LSM } & \multirow[t]{2}{*}{$11 \mathrm{a} 5 \mathrm{~m}$} & \multirow[t]{2}{*}{$\mathrm{F}$} & \multirow[t]{2}{*}{ Pais HIV+ } \\
\hline & $45 \mathrm{a}$ & & & & \\
\hline
\end{tabular}

enganar ele por muito tempo... ele também já guarda segredo. mãe de LSS

Ela tem o direito de saber, porque se fosse comigo e minha mãe não contasse eu ficaria muito magoada! mãe SBM

Houve cuidadoras que alegaram dificuldades por parte da criança para colaborarem com o tratamento e uma referiu que o momento parecia-lhe oportuno pelo fato da criança estar crescendo.

Ele precisa saber porque não quer tomar remédio de jeito nenhum... todo dia eu fico desesperada, ele sai correndo, fica escondido, outro dia ele subiu na laje de casa e não descia de jeito nenhum! Quem sabe ele não se conscientiza mais! avó de RCC
Acho que agora o momento é ideal porque ele já está crescendo, se esperar eu tenho medo de que ele fique pior e que ele comece a cobrar... mãe de RSR

Além disso, a avaliação psicológica proposta, o preparo prévio e a ajuda do profissional para o processo também atuaram como elementos encorajadores para a divulgação da doença.

Eu achei tão bom você conhecer ela melhor, preparar, conversar com a gente antes! mãe de PPBA

É bom que a senhora esteja preparando ele, porque sozinha eu não ia ter coragem. mãe de GHS

Eu acho que a ajuda de vocês é fundamental, quando você e o Dr S. decidirem que ele está preparado eu vou confiar! mãe de MRS 


\section{A mudança de olhar}

Outras intervenções foram realizadas visando minimizar as angústias e temores dos cuidadores acerca da revelação diagnóstica da criança. Nesse sentido, a devolução dos dados obtidos a partir da avaliação que havia sido feito com os pacientes, possibilitou aos responsáveis uma maior sensibilização frente à comunicação diagnóstica, por entenderem que o segredo da doença pode adquirir simbolismos incompreensíveis, desencadeando angústias e prejuízos ao desenvolvimento emocional.

Agora você falando faz sentido, porque quando ele pega uma virose ela pensa que tem alguma coisa muito séria e acha que vai morrer! mãe de RSR

Depois que a gente conversou da última vez eu comecei a tratar ela diferente... não sei por que, mas ela não ta mais brigando, nem aprontando. avó de MEOS

Eu tenho que falar para o pai dela também que não é bom ela ser tratada como o bebê da casa. Pensando bem, na escola a professora diz que ela é muito esperta, até cuida das crianças menores! mãe de PBPA

A apresentação aos cuidadores dos conteúdos que se mostraram mais relevantes nas produções gráficas e verbais das crianças (histórias, desenhos e brincadeiras) serviu para exemplificar em que medida o silêncio sobre a enfermidade invade o psiquismo infantil através da construção de fantasias assustadoras e angustiantes. Essa apresentação teve especial importância e foi conduzida com cuidado, porque os familiares constataram que muitas de suas atitudes não foram capazes de preservar e proteger suas crianças como supostamente haviam imaginado.

\section{Outras dores que necessitam ser acolhidas antes da revelação diagnóstica}

Além dos relatos sobre preocupações e fantasias acerca da comunicação diagnóstica às crianças, esses encontros também possibilitaram a verbalização dos dramas pessoais vivenciados por esses familiares, como experiências de isolamento, discriminação e solidão em decorrência da Aids.

Minha vida mudou radicalmente, eu me tornei uma pessoa sozinha. mãe de LSS

Entre os casos estudados, observou-se que os pais, ao se defrontarem com o problema da revelação aos seus filhos, acabam revivendo experiências passadas, remetendo-os à ocasião em que receberam o diagnóstico do HIV, normal- mente de forma inadequada e sem preparo prévio. Supondo semelhanças entre as histórias, eles tendiam a imaginar que as crianças sofreriam o mesmo impacto emocional e, portanto, não suportariam a dor e o sofrimento desencadeados por saberem-se portadores dessa enfermidade.

Eu descobri quando estava com 2 meses de gravidez, o médico me falou sem me preparar e eu estava sozinha, chorei a gravidez toda! Eu não posso imaginar que ela sinta o que eu senti. mãe de VDMS

Depois de eu saber que tinha Aids, eu falei da doença para algumas pessoas, daí eu percebi que as coisas mudaram... tem gente que olha com desprezo, me dói muito porque os outros podem desprezar ela, como aconteceu comigo... Mãe de SBM

Além disso, a influência do HIV nos relacionamentos afetivos e sexuais dessas mães-mulheres e a vergonha por conviver com corpos transformados pela lipodistrofia foram temas relevantes e que precisaram ser acolhidos.

Eu sei que hoje as pessoas me ajudam mais... mas eu era alegre, de bem com a vida, eu tinha um corpo bonito... agora eu tenho vergonha de me olhar no espelho... eu nunca mais vou conseguir namorar, me relacionar com alguém! mãe de GHS

No caso das avós que trouxeram seus netos para os atendimentos, os sentimentos de solidão e inconformidade pela perda dos filhos, foram narrativas marcantes e que estiveram presentes ao longo das entrevistas.

... primeiro eu ficava triste todos os dias, é difícil a gente perder os filhos. Hoje eu estou mais conformada. avó de MIM

Eu não aceito o que aconteceu com a minha filha... ela só me contou quando estava morrendo... eu não vou me conformar se eu perder a minha neta também! avó de MEOS

Obviamente, todas essas experiências cotidianas vivenciadas pelos familiares foram elementos fragilizantes e que os incapacitaram para conversar sobre a doença e tratamento, e sobretudo, para suportar as inquietações que seriam suscitadas em seus filhos pelo conhecimento de sua condição sorológica.

\section{O suporte familiar: a importância do fortalecimento dos cuidadores}

A avaliação da rede de apoio familiar e da estrutura psicológica dos responsáveis foi considerada imprescindível, tendo em vista a importância do acolhimento de angústias e o apoio de possíveis dúvidas ou demais necessidades apresentadas pelo paciente após a abertura diagnóstica. 
Para a mãe de uma das crianças, que apresentava escassos recursos internos para suprir as necessidades da filha após a revelação diagnóstica, optou-se pela realização de outras entrevistas, além do encaminhamento para avaliação psiquiátrica e psicológica, com o intuito de ajudá-la a superar quadro depressivo importante, associado a sentimentos de culpa pela infecção da filha.

Antes eu era alegre, feliz e hoje em dia eu não tenho mais razão para viver. mãe de SBM

\section{A participação dos cuidadores para o processo da revelação diagnóstica}

Os participantes tiveram a possibilidade de expressar suas opiniões quanto à pessoa mais preparada para iniciar o diálogo com as crianças, incluindo familiares e profissionais, além de sugestões sobre o desenvolvimento do processo.

\section{Quem?}

Dessa amostra 05 mães e 03 avós alegaram que a psicóloga é a pessoa mais indicada para conversar com a criança sobre o HIV, 04 mães disseram que o médico e a psicóloga devem estar juntos no momento da revelação, das quais 02 delas querem estar presentes. Uma (01) mãe sugeriu que o médico deve contar para o filho, 01 mãe quer fazer a revelação com a ajuda da psicóloga, 01 com a ajuda de algum profissional e 08 não souberam responder: 03 pais, 03 mães, 02 avós.

\section{Como?}

Vinte e um (21) entrevistados não souberam escolher a melhor forma de conversar com a criança. Apenas duas mães sugeriram falar a verdade, ou seja, que foram responsáveis pela doença e infectadas por não terem usado preservativos durante relações sexuais.

\section{O segredo}

A segurança de que a criança conseguiria guardar sigilo foi um dos pontos abordados durante a entrevista de planejamento do processo da revelação diagnóstica. Os relatos colhidos acerca dessa questão foram fundamentais, pois determinaram o encaminhamento às modalidades de intervenção, ou seja, revelação diagnóstica completa (com nomeação do vírus e da doença) ou parcial (apenas uma infecção viral). No caso dos pacientes que não tinham essa capacidade, esclareceu-se aos pais que as intervenções seriam limitadas à elucidação sobre a importância da tomada das medicações e dos mecanismos de ação dos vírus no organismo, sem nomeação do diagnóstico do HIV. Apenas uma mãe optou, num primeiro momento, pela revelação diagnóstica parcial, mesmo sabendo que o filho guardaria segredo.

$\mathrm{Na}$ visão dos responsáveis, a maioria das crianças conseguia manter segredo sobre situações do cotidiano quando solicitado por um adulto de confiança. Alguns cuidadores disseram que suas crianças não eram capazes e outras entrevistadas não souberam responder pelo fato de nunca atentaram para tal comportamento.

Eu nunca tinha pensado nisso... ah ele guarda segredo sim, porque ele fica muito bravo quando eu faço comentário de outras pessoas... Daí ele me diz: - oh mãe tem coisas que a gente não pode ficar falando! mãe de GHS

Eu não tinha reparado, mas acho que ela fez a primeira comunhão e foi se confessar com o padre... Não falou o que eles conversaram de jeito nenhum! mãe de LSM

Ele sabe que tem coisas que não pode falar, quando tem amiguinho em casa, ela vem tomar o remédio escondido! avó de RCC

Ela não guarda segredo não, tem a boca mole... avó de MEOS

Eu não sei não... nunca reparei. mãe de SSX

\section{O segredo do segredo}

\section{Conhecimento sobre a origem e o nascimento dos bebês}

Tendo em vista que os temas a serem trabalhados no decorrer do processo também envolveriam as formas de transmissão da infecção, considerou-se prudente saber se o paciente possuía noções sobre a vida sexual e reprodutiva e se os pais autorizariam a falar sobre esses assuntos.

Nesse sentido, alguns cuidadores alegaram que as crianças conheciam a origem e o nascimento dos bebês e outras possuíam noções parciais ou representações distorcidas sobre sexualidade. Um dos entrevistados não soube referir e os demais comentaram que os filhos desconheciam ou nunca haviam demonstrado curiosidade em torno da temática. Apesar de todos os responsáveis concordarem com a abordagem dessas questões, no caso dos pequenos, decidiu-se que as explicações sobre as formas de transmissão do vírus seriam introduzidas mediante a expressão de curiosidade ou interesse por parte 
criança ao longo do trabalho. Exemplos de conhecimento parcial ou distorcido:

Aprendeu o que é transar vendo televisão, faz os gestos, mas pensa que corta a barriga para o nenê nascer! mãe de MRS

O papai coloca uma semente na vagina da mamãe para poder fazer os nenês. mãe de PPBA

Mas a Tuca falou que ela comeu semente de melancia e a minha colega que é cegonha. mãe de LATR

Bebês nascem pela barriga (mãe mostrou cicatriz de cirurgia de apendicite) e são feitos porque o homem e a mulher se beijam e namoram. mãe de GHS

Eu já expliquei para ele sobre o uso de preservativos... Ele pergunta se as pessoas que se beijam na televisão estão fazendo sexo! mãe de GSP

Considerando esta possibilidade, os cuidadores foram questionados sobre suas reações frente à curiosidade da criança sobre a história de infecção dos pais. Apenas duas das mães mostraram-se inquietas e preocupadas com a possibilidade dos filhos lhes questionarem sobre a forma como adquiriram a enfermidade. Num casal sorodiscordante (mãe soropositiva e pai soronegativo), a mãe referiu que o marido foi seu único parceiro sexual, negou uso de drogas injetáveis, transfusões de sangue ou qualquer outra forma de exposição e relatou preferir supor que a contaminação ocorreu na ocasião de o nascimento da criança, pois tomou banho descalça no hospital. Na outra situação, a mãe acredita que adquiriu o HIV também num hospital onde foi submetida a uma intervenção cirúrgica.

Eu não sei... eu vou contar para ele a verdade, essa é a minha verdade! mãe de WGB

Eu ainda não acredito, eu penso que foi quando eu tive um aborto, eles devem ter me aplicado alguma coisa... o hospital não era muito limpo, e depois meu marido nunca foi de sair com outro homem. mãe de LSM

\section{O consentimento dos familiares}

No final das entrevistas devolutivas, após a realização da avaliação psicológica, todos os pais e/ou responsáveis confirmaram sua autorização para que o processo da revelação diagnóstica fosse iniciado. Essa autorização incluía o acordo com a decisão tomada, consciência sobre a importância da comunicação do diagnóstico e preparação para o esclarecimento de dúvidas e apoio emocional diante de possíveis angústias apresentadas pelas crianças em outros contextos.

\section{$O$ enquadre}

O enquadre no acompanhamento do processo de revelação diagnóstica teve como objetivo estabelecer os limites e as condiçõos para a realização e a continuidade do trabalho. Foram propostos atendimentos semanais ou quinzenais, posteriores ao momento da abertura diagnóstica, com cinquenta minutos de duração e limite de tempo estabelecido de aproximadamente 6 (seis) meses, com continuidade do processo de acordo com as necessidades apresentadas pelos pacientes. Agendamento de consultas extras foi oferecido nos casos em que os familiares observassem mudanças comportamentais na criança.

Posteriormente os responsáveis conheceram as técnicas utilizadas e as estratégias de intervenção que incluiriam o material psicopedagógico destinado para apoiar a comunicação sobre as informações da doença e tratamento. Além disso, esclareceu-se que no decorrer do acompanhamento pós-revelação, seriam utilizados outros instrumentos para intervenção e interação com a criança, como jogos, brinquedos e materiais gráficos.

\section{Outras orientações e esclarecimentos que precederam a abertura diagnóstica}

Após a revelação diagnóstica, os cuidadores foram orientados para estimularem nas crianças a verbalização com espontaneidade sobre sua doença, tratamento ou quaisquer procedimentos aos quais são rotineiramente submetidos. Buscou-se demonstrar o quanto é fundamental que o adulto converse e contextualize a criança não apenas sobre a doença, mas sobre os acontecimentos de sua vida, procurando observar e apreender seus modos de comunicação e suas formas prediletas de expressão. A maioria delas não consegue verbalizar explicitamente suas dúvidas e, naturalmente, tende a manifestar seus sentimentos através de jogos, desenhos e brincadeiras. Observar os sentidos particulares dos movimentos da criança e valorizar suas percepções e pensamentos são atitudes indispensáveis para quem pretende uma aproximação verdadeira da riqueza que constitui o universo infantil.

Por último, os responsáveis foram informados que, independentemente do impacto suscitado na criança pelo conhecimento de sua infecção, eles receberiam apoio emocional por parte da equipe responsável. 


\section{Discussão}

As recomendações sobre a revelação diagnóstica às crianças e adolescentes soropositivos preconizadas pelo instituto de saúde de Nova York ${ }^{1}$ destacam a importância da colaboração dos cuidadores para a elaboração de um plano que atenda às necessidades individualizadas da família e da criança Moodley et al. e realçam que as entrevistas motivacionais podem ser úteis para facilitar as discussões com os familiares que não se sentem preparados para a divulgação do diagnóstico às crianças ${ }^{11}$. Tal qual no presente estudo, os pontos centrais sugeridos para serem trabalhados com os cuidadores, incluem o conhecimento de suas preocupações, bem como informações claras sobre riscos e benefícios da revelação.

Compreender os motivos pelos quais os cuidadores relutam em revelar o diagnóstico às suas crianças e legitimar suas preocupações são condutas que promovem uma parceria entre os familiares e a equipe facilitando o desenvolvimento de uma relação mais harmoniosa entre profissionais de saúde e cuidadores.

Como panorama geral, os fatores que definem a decisão pelo sigilo sobre a infecção são similares aos dos pais de crianças acometidas por outras doenças crônicas ${ }^{1}$. Frequentemente eles receiam que o conhecimento da enfermidade possa causar impacto negativo na saúde mental dos filhos, afetando sua vontade de viver ${ }^{1,9}$. Outros estudos confirmam que os responsáveis evitam revelar a doença porque temem que elas sejam rejeitadas e sujeitas a preconceitos e isolamento social ${ }^{5,10}$. Na África do Sul, uma pesquisa realizada com 165 cuidadores de crianças soropositivas acompanhadas num ambulatório de Aids revelou que $73 \%$ dos participantes justificaram a decisão pelo sigilo da doença devido ao medo da criança não guardar segredo, especialmente entre os amigos e crianças da escola ${ }^{11}$.

No presente trabalho, 11 cuidadores relataram apreensões com possíveis reações de revolta e rebeldia, seguidas pelo medo de que a criança possa sofrer algum tipo de preconceito e isolamento social, sugerindo a necessidade de se ampliar o debate sobre essa temática e o combate ativo às formas de exclusão e estigma baseados na condição sorológica desses pacientes ${ }^{1,5,12}$. É possível que muitos responsáveis sintam-se despreparados para iniciar a conversa sobre a infecção supondo que não conseguiriam responder possíveis questionamentos relacionados a expectativas de vida e planos futuros ${ }^{13}$. Há ainda, aqueles que se julgam frágeis para lidar com as próprias emoções enquanto compartilham informações dolorosas ${ }^{13}$.

De uma maneira geral, os fatores mencionados pelos responsáveis neste estudo para a divulgação da doença, são os mesmos relatados em outros estudos ${ }^{1,14}$ dentre eles, a curiosidade e direitos da criança, sua capacidade em guardar segredo e os benefícios clínicos sobre a divulgação, junto com a possibilidade de participarem mais efetivamente do tratamento ${ }^{14,15}$ Achados adicionais a respeito deste tema incluíram pressões por parte da equipe médica, antes de iniciar o tratamento, e as próprias experiências infantis negativas dos cuidadores mediante segredos sobre adoção ou suicídio ${ }^{15}$. Outros pesquisadores associaram a comunicação da doença com a proximidade da vida sexual ou pela simples tentativa de corrigir uma intervenção inadequada e descuidada, realizada abruptamente por um profissional ${ }^{5}$.

Um aspecto valioso e que amplia as constatações realizadas por outros autores, diz respeito ao destaque dado pelos familiares na avaliação psicológica realizada previamente com as crianças e no preparo e apoio recebido pelos profissionais. Para a grande maioria dos cuidadores esses aspectos foram fundamentais e atuaram como elementos encorajadores para a divulgação da doença. No estudo realizado na África do Sul, apenas $25 \%$ dos 165 participantes referiram ter discutido os problemas da divulgação com algum profissional da saúde, sugerindo que diante deste cenário, a divulgação do HIV pediátrico requer maior atenção no âmbito das consultas clínicas $^{14}$.

Por um lado, a tomada de consciência sobre as nuances e singularidades de cada uma das crianças e a compreensão de que o segredo da infecção contribui negativamente para o seu crescimento são intervenções que instrumentalizam os cuidadores para que desempenhem adequadamente a função de acolhimento junto às situações adversas que poderão envolver o conhecimento da doença. Por outro lado, também merece atenção identificar a fragilidade emocional desses pais e/ou responsáveis, pois diante de vivências ameaçadoras e, por vezes, traumatizantes relacionadas ao HIV, eles também precisam ser acompanhados em seus medos, culpas e principais preocupações. Assim, o propósito dessas entrevistas residiu também em tentativas de ajudar esses cuidadores a compreenderem as cenas angustiantes associadas às situações desagradáveis e sofridas suscitadas pela doença, através da identificação, domínio e controle sobre os acontecimentos dolorosos vividos. 
Quanto à participação dos familiares acerca de quem é pessoa mais adequada para iniciar a conversa sobre o HIV com os filhos, observou-se que a maioria das respostas fez menção ao médico, psicólogo ou ambos profissionais. Diferentemente do presente trabalho, no estudo realizado por Moodley et al. ${ }^{11}$, 83\% dos entrevistados consideraram que a mãe ou o cuidador principal devem assumir a responsabilidade para discutir com a criança sobre a doença e apenas 16\% referiram que os médicos, enfermeiros ou conselheiros são as pessoas mais indicadas para fazerem a revelação ${ }^{11}$.

Em relação à melhor forma para contar aos pacientes sobre a enfermidade, os entrevistados não souberam opinar e mais uma vez referiram que os profissionais são as pessoas mais capazes para dar explicações coerentes e adequadas às necessidades de suas crianças.

Além desses aspectos, ainda foram discutidos com os pais os benefícios e os riscos de revelar o diagnóstico da infecção pelo HIV, o encaminhamento para o apoio emocional em caso de necessidade, bem como as estratégias de comunicação parcial às crianças que não conseguem guardar segredo. A divulgação parcial também pode ser eficaz para ajudar os familiares que não estão prontos para usar os termos "HIV" ou "Aids"11,12.

Os pais devem saber que os pacientes conhecedores de sua condição sorológica sentem-se menos solitários, confiam nas pessoas à sua volta, participam e colaboram com o tratamento e intervenções que são realizadas. Quanto aos familiares, a experiência também tem demonstrado que após a revelação diagnóstica, os pais mostram-se aliviados e satisfeitos e os profissionais ficam mais à vontade, durante as consultas, para conversarem abertamente com os pequenos pacientes sobre os exames, medicações e coletas de sangue que são necessários para o seu acompanhamento clínico e tratamento.

Finalmente, apesar dessas entrevistas terem possibilitado uma oportunidade para sensibilizar os cuidadores sobre as necessidades específicas da criança no contexto do HIV/aids, quando os pais percebem que a premissa central do trabalho focaliza o desenvolvimento e o bem-estar da criança como um todo, observa-se maior confiança, tranquilidade e desejo em colaborar integralmente na condução do processo. Isto quer dizer que o entendimento do paciente dentro de uma perspectiva abrangente de cuidado torna-se cada vez mais indispensável para a melhora do tratamento em todas as suas dimensões.

Essas considerações apontam para a necessidade de diretrizes sobre a revelação diagnóstica nos serviços, com o estabelecimento de políticas e estratégias definidas e adequadas às necessidades de cada criança e seu grupo familiar. A clínica da Aids pediátrica não requer apenas conhecimentos atualizados, mas o envolvimento e a disponibilidade de todos os cuidadores implicados, com novas propostas de intervenções que contemplem a complexidade dos fatores quando se comunica à criança sobre sua condição sorológica.

\section{Conclusão}

A técnica da entrevista com os familiares utilizada neste estudo foi um instrumento fundamental na construção do planejamento para a revelação diagnóstica das crianças e adolescentes desconhecedores de sua condição sorológica. No decorrer desses encontros, a participação dos cuidadores e as informações obtidas forneceram subsídios valiosos e relevantes para o direcionamento do trabalho, além de ter possibilitado o estabelecimento de um vínculo receptivo e favorável, capaz de minimizar inibições que poderiam ser prejudiciais à continuidade do processo.

Dessa forma, compreender e analisar os conteúdos objetivos e subjetivos dos cuidadores de pacientes que vivem com o HIV, considerando a complexidade de variáveis envolvidas em torno do silêncio sobre a infecção, pode fornecer subsídios para uma melhor definição de como proceder no manejo do processo da revelação diagnóstica. Assim, para além da coleta de informações, que são indispensáveis para a condução e desenvolvimento da revelação diagnóstica, entende-se que a principal função do profissional é promover um encontro onde esses cuidadores sintam acolhidas suas angústias, preocupações e temores. 


\section{Colaboradores}

E Galano teve participação na concepção e planejamento do projeto de pesquisa, coleta de dados, análise, redação e revisão crítica. MA De Marco e DM Machado foram orientadores dessa pesquisa e participaram na revisão da literatura, elaboração do projeto, análise e discussão de dados. RCM Succi e MH Silva colaboraram no desenho do estudo na discussão dos resultados e revisão do artigo.

\section{Referências}

1. New York State Department of Health AIDS Institute. Disclosure of HIV to Perinatally Infected Children and Adolescents, 2009. [site na Internet]. [acessado em 2012 set 14]. Disponível em: http:// www.hivguidelines.org/clinical-guidelines/infantschildren/disclosure-of-hiv-to-perinatally-infectedchildren-and-adolescents/

2. Brasil. Ministério da Saúde (MS). Secretaria de Vigilância em Saúde. Programa Nacional de DST e Aids. Guia de tratamento clínico da infecção pelo HIV em pediatria. Secretaria de Vigilância em Saúde, Programa Nacional de DST e Aids. 3a Edição. Brasília: MS; 2009.

3. Wiener L, Mellins CA Marhefka S, Battles HB. Disclosure of an HIV diagnosis to children: history, current research, and future directions. J Dev Behav Pediatr 2007; 28(2):155-166.

4. Guerra CPP, Seidl EMF. Crianças e adolescentes com HIV/Aids: revisão de estudos sobre revelação do diagnóstico, adesão e estigma. Paidéia (Ribeirão Preto) 2009; 119(42):59-65.

5. Marques HHS, Silva NG, Gutierrez PL, Lacerda R, Ayres JRCM, DellaNegra M, Franca Júnior I, Galano E, Paiva V, Segurado AAC, Silva MH. A revelação do diagnóstico na perspectiva dos adolescentes vivendo com HIV/AIDS e seus pais e cuidadores. Cad Saude Publica 2006; 22 (3):619-629.

6. Guba EG, Lincoln YS. Fourth generation evaluation. Newbury Park: Sage; 1989.

7. Wiener LS, Battles HB, Heilman N, Sigelman CK, Pizzo PA. Factors associated with disclosure of diagnosis to children with HIV/Aids. Pediatr AIDS HIV Infect 1996; 7(5):310-324.

8. Seidl EMF, Rossi WS, Viana KF, Meneses AKF, Meireles E. Crianças e adolescentes vivendo com HIV/Aids e suas famílias: aspectos psicossociais e enfrentamentos. Psicologia: Teoria e Pesquisa 2005; 21(3):279-288.
9. Brasil. Ministério da Saúde. Conselho Nacional de Saúde. Resolução nº. 196/1996. Diretrizes e Normas Regulamentadoras de Pesquisas Envolvendo Seres Humanos. Diário Oficial da União 1996; out 10.

10. Conselho Federal de Psicologia (CFP). Resolução no 016 de 20 de dezembro de 2000 do Conselho Federal de Psicologia. Dispõe sobre a realização de pesquisa em Psicologia com seres humanos. Brasília: CFP; 2000.

11. Moodley K, Myer L, Michaels D, Cotton M. To the Editor: Most paediatric HIV infections in South Africa. Paediatric HIV disclosure in South Africa caregivers'perspectives on discussing HIV with infected children. March 2006; 96(3).

12. Enhancing Care Initiative/Brazil - ECI/BR. Vulnerabilidade e cuidado: a atenção psicossocial na assistência à saúde de adolescentes vivendo com HIV/ Aids. 2003. [site na Internet]. [acessado 2012 set 3]. Disponível em: http://www.eci.harvard.edu/teams/ brazil/index.html

13. Lipson M. Disclosure of diagnosis to children with human immunodeficiency virus or acquired immunodeficiency syndrome. J Dev Behav Pediatr 1994; 15(3):61-65.

14. Slavin LA, O’Malley JE, Koocher GP, Foster DJ. Communication of the cancer diagnosis to pediatric patients: impact on long-term adjustment. Am J Psych 1982; 139(2):179-183.

15. Lester P, Chesney M, Cooke M, Whalley P, Perez B, Petru A, Dorenbaum A, Wara D. Diagnostic disclosure to HIV-infected children: how parents decide when and what to tell. Clinl Child Psych Psychiatry 2002; 7(1):85-99.

Artigo apresentado em 03/05/2011

Versão final apresentada em 21/06/2011 